\title{
Proksimal tibia medial açık kama iki planlı retrotüberkül osteotomisi: Kamalı plak ile tespit
}

\section{The biplanar retrotubercle medial opening wedge proximal tibial osteotomy: fixation plates with wedge}

\author{
İrfan Esenkaya', Burak Özturan²
}

\author{
'Ortopedi ve Travmatoloji Uzmanı, Emekli Öğretim Üyesi \\ ${ }^{2}$ S.B. İstanbul Medeniyet Üniversitesi, Göztepe Eğitim ve Araştırma Hastanesi, Ortopedi ve Travmatoloji Kliniği, İstanbul
}

\begin{abstract}
Tek planda yapılan medial açık kama osteotomi (MAKO) uygulamalarından sonra patella infera (baja) gelişebilir. Gaasbeek ve ark. tibial tüberkülün proksimal fragmanda bırakıldığı osteotomi tekniğini MAKO'da uygulayarak bu yöntemin patella infera oluşumunu engellediğini gösterdiler. Lobenhoffer ve ark., patella infera olgularında uyguladıkları iki planlı (biplanar) osteotomilerde, patellar tendonun yapışma yerinin arkasındaki kemik kesisinin yukarıya değil aşağıya yönlendirilmesi ile, osteotomi sonrası ekstansör mekanizmada oluşabilecek değişikliklerin önüne geçilebileceğini belirttiler. Takip eden yıllarda yapılan, tibial tüberkülün proksimal veya distal fragmanda bırakıldığı osteotomi uygulamalarını kıyaslayan çalışmalarda, tibial tüberkülün proksimal fragmanda bırakıldığı osteotomi uygulamalarında patellar tendon boyunda değişiklik olmadığı için patellofemoral osteoartritin ilerlemesini önlediği yönünde sonuçlar bildirildi. Yazarların tecrübeleri de bu yöndedir. Ameliyat öncesi patella infera olmadığı takdirde, tibial tüberkülün proksimal fragmanda bırakıldığı osteotomiler patellar tendon boyunda değişiklik yapmazlar.
\end{abstract}

Anahtar sözcükler: proksimal tibial osteotomi; yüksek tibial osteotomi; medial açık kama osteotomisi; retrotüberkül osteotomisi; iki planlı osteotomi; medial gonartroz
Patella infera (baja) may develop after monoplanar applications of medial opening wedge osteotomy (MOWO). Gaasbeek et al. demonstrated that the applications of an osteotomy technique in which the tibial tubercle is left in the proximal fragment in MOWO prevents the formation of patella infera. Lobenhoffer et al. found that the applications of biplanar osteotomies in patella infera cases prevents the changes in extensor mechanism after the osteotomy. This was possible by directing the bone incision behind the patellar tendon downwards rather than upwards. In the follow-up studies, the osteotomy applications in which the tibial tubercle was left either in the proximal or distal fragment were compared. It was found that the proximal application did not change the length of the patellar tendon in the proximal fragment and therefore prevented the progression of patellofemoral osteoarthritis. The experiences of the authors also support these findings. If there is no patella infera before the surgery, osteotomies in which the tibial tubercle is left in the proximal fragment do not change the patellar tendon length.

Key words: proximal tibial osteotomy; high tibial osteotomy; medial opening wedge osteotomy; retrotubercle osteotomy; biplanar osteotomy; medial gonarthrosis

\section{TiBiAL TÜBERKÜLÜN PROKSIMAL FRAGMANDA BIRAKILDIĞI RETROTÜBERKÜL OSTEOTOMISi}

Diz eklemindeki varus dizilim bozukluğuna ilave olarak, medial tibiofemoral kompartmandaki osteoartritik değişikliklere ek olarak patellofemoral (PF) kompartmanda da problemi olan hastalar için çeşitli proksimal tibia valgus osteotomi teknikleri tanımlanmıştır. Bu uygulamalardaki genel amaç, patellar tendon boyundaki kısalma ve gerilmelere engel olarak PF basıncı azaltmaktır. Jacob ve Murphy'nin kapalı kama osteotomisinde tüberkül yüksekliğini, patella/patellar tendon oranını ve $\mathrm{Q}$ açısını değiştirmediği için uyguladıkları retrotüberkül osteotomi yöntemi daha sonra Murphy tarafindan yaygın olarak tanıtılmıştır. ${ }^{[1]}$ Gaasbeek ve ark., tibial tüberkülün proksimal fragmanda bırakıldığı osteotomi tekniğini medial açık kama osteotomisinde (MAKO) de uygulayarak bu yöntemin patella infera (patella baja) oluşumunu engellediğini göstermişlerdir. ${ }^{[2]}$ Lobenhoffer ve ark., patella infera olan olgularda, patellar tendonun yapışma yerinin arkasındaki kemik kesisinin yukarıya değil

- İletişim adresi: Prof. Dr. İrfan Esenkaya, SANTE Tıp Merkezi, Ortopedi ve Travmatoloji Bölümü. Fener Kalamış Caddesi, No: 32, Kalamış, Kadıköy, İstanbul Tel: 0532 - 3218681,0530 - 8632786 e-posta: iesenkaya@hotmail.com

- Geliş tarihi: 20 Ocak $2020 \quad$ Kabul tarihi: 19 Şubat 2020 
aşağıya yönlendirilmesi ile osteotomi sonrası ekstansör mekanizmada oluşabilecek değişikliklerin önüne geçilebileceğini belirterek osteotomi sonrası tuberositas tibianın ön-arka planda tibia gövdesine bir lag (çektirme) vidasıyla tespit edilmesini önermişlerdir. ${ }^{[3]}$ Gaasbeek ve ark., tibial tüberkülün kaidesinde en az $1 \mathrm{~cm}$ 'lik kemik devamlılığı kalacak şekilde tibianın osteotomize edilmesini önermektedirler. Proksimal parçada kalan tibial tüberkülün gagamsı çıkıntısının, distale doğru en az 2,5 $\mathrm{cm}$ uzunluğunda olması ve distraksiyon (açma) miktarı arttıkça bu parçanın ayrıldığı alttaki yüzeyle en az 2 cm'lik kısmının üst üste gelecek şekilde uzun bırakılması tavsiye edilmektedir. Yazarlar tespit için medialden TomoFix (Synthes, Oberdorf, Switzerland) plağı uyguladıklarını belirtmişlerdir. İlave olarak ön-arka düzlemde, tibial tüberkül karşı korteksi de tutacak şekilde tibiaya kortikal vida ile tespit edilir. ${ }^{[2]}$ Gaasbeek ve ark. ${ }^{[2]}$ tarafindan tarif edilen bu teknik modifiye edilerek bölümün yazarları tarafından da uygulanmaktadır. ${ }^{[4-6]}$ illerleyen yıllarda, tibial tüberkülün proksimal fragmanda bırakıldığı osteotomi tekniği ile patellar tendon boyunda değişiklik olmadığı ve patellofemoral osteoartrit gelişimini artırmadığı yönünde çalışmalar bildirilmiştir. Yöntem; iki planlı aşağı inen (biplanar descending) osteotomi ya da distal tuberositas (tibial tüberkül) osteotomisi olarak da isimlendirilmektedir. ${ }^{[7-12]}$

\section{ENDIKASYON VE KONTRENDIKASYONLAR}

Diğer proksimal tibial osteotomi (PTO) uygulamalarında olduğu gibi, MAKO uygulamalarında da uygun hasta seçimi ve doğru cerrahi teknik uzun dönemde alınacak başarılı sonuçları doğrudan etkilemektedir. Başarılı sonuç göstergesi; dizilim bozukluğu düzeltilmiş, ağrısız, stabil ve hareket açıklığı korunmuş veya artırılmış bir dizdir. Amaç; varus dizlerde medial tibiofemoral kompartmana gelen yükleri azaltmak için, medial sıfır kabul edildiğinde mekanik eksenin \%62-62,5 lateralden geçecek şekilde alt ekstremite diziliminin düzeltilmesidir. ${ }^{[3,13]}$

Tek plandaki (monoplanar) proksimal tibia medial açık kama osteotomisi (PTMAKO) için geçerli olan genel endikasyon ve kontrendikasyon kuralları, [3,13-20] retrotüberkül osteotomisi için de geçerlidir. Tekniğin, özellikle patellofemoral problemi olan hastalara da uygulanabilmesi gibi endikasyon alanını genişletici özellikleri de vardır. ${ }^{[3-12]}$

Ameliyat öncesi; hastanın yaşı, cinsiyeti, eklem hareket açıklığı, diz ekleminin mediolateral ve anteroposterior stabilitesi (dengesi), osteoartritin derecesi değerlendirilmelidir. Ayakta yük verirken çekilen her iki diz önarka (AP) ve yan (LAT) grafilere ilaveten kalça-ayak bileğini gösterir ortoröntgenografilerin değerlendirilmesi önemlidir. Genel anlamda MAKO uygulamalarında başarılı sonuç alınması için; 65-70 yaşın altındaki, tek kompartman tutulumlu, varus dizilim bozukluğu olan, aşırı kilosu olmayan ve hareket açıklığı en az $100^{\circ}$ (ideali $120^{\circ}$ ) olan hastaların tercih edilmesi önerilmektedir. [3,21] Belirli bir yaşın altında osteotomi yapılır diye kesin saptanmış bir kronolojik yaş yoktur. Altmış yaş en çok tekrar edilen yaştır. Hastanın aktivite seviyesi, yaşam tarzı, gelecekten beklentisi, genel sağlık koşulları ve eşlik eden hastalıkları da göz önünde bulundurulmalıdır. [13] Üst yaş sınırı, hastanın aktivitesine bağlı olarak, 79'a kadar çıkabilmektedir. ${ }^{[15]}$ Özellikle aktif ve kemik yapıSı güçlü olan erkek hastalarda yaş sınırı yükseltilebilir. Bölüm yazarlarının üst yaş sınırı 74'tür. Fleksiyon kontraktürü $15^{\circ}$ 'nin altında olmalıdır. Her üç kompartmanın da tutulduğu romatoid artritli hastalar, aşıı instabil (dengesiz) dizler ile $20^{\circ}$ 'nin üzerinde varus deformitesi olan dizler aşırı bağ laksitesi (gevşekliği) ve subluksasyonla beraber olacakları için, bu dizlere osteotomi yapılmamalıdır. Subluksasyon göreceli bir kontrendikasyon olup deformite düzeltilse dahi yan bağ kompleksinde gevşeme ile sonuçlanabilir. Aşırı derecede varus deformitesiyle beraber tibianın subluksasyonunun $1 \mathrm{~cm}$ 'nin üzerinde olması durumunda kesin kontrendikasyon söz konusudur. ${ }^{[13]}$

Eskiden ön çapraz bağ (ÖÇB) ve arka çapraz bağ (AÇB) yetmezlikleri veya yaralanmaları göreceli veya kesin kontrendikasyon oluşturmakta idi. Günümüzde, ÖÇB veya AÇB yetmezliği veya yaralanmalarında da, PTO'nun frontal ve sagittal planlardaki deformiteyi eş zamanlı olarak düzeltebilme etkisi nedeniyle, uygulama daha genç yaşlara kaydırılmıştır. ${ }^{[3,13]}$

Aşıı kilolu hastaların PTO ile tedavisi tartışmalı bir konudur. Aşırı şişmanlık birçok ortopedik hastalığın cerrahi tedavisinde sonuçları olumsuz yönde etkilemektedir. ${ }^{[13,21]}$

Bacak uzamasının kontrendike olduğu durumlarda ve kesi bölgesinde (medialde) cilt problemleri olduğunda MAKO uygulanmamalıdır. Nikotin göreceli kontrendikasyon olarak kabul edilmiştir. ${ }^{[3,15]}$ Hasta sigara kullanıyor ise, sigarayı ameliyattan 3-4 ay önce bırakması önerilmelidir. Sigara içen hastalarda kaynama problemi olabileceği konusunda hastalar önceden bilgilendirilmelidir.

Medial tibiada veya femurda birkaç mm'den fazla kemik kaybının radyolojik olarak saptanması kontrendikasyon oluşturur. Medial kompartmandaki kemik desteği yetersiz ise, ameliyat sonrası gelen yük altında kalan her iki tibial platonun konuma göre uyum göstermeleri mümkün değildir. Bu durumda, tibiofemoral temas nispeten çıkıntılı olan tibial dikensi çıkıntılar (eminentialar) üzerinden aşağı-yukarı inme-çıkma hareketi (tahterevalli etkisi) şeklinde olur. ${ }^{[13]}$ 
Yürüme esnasında laterale veya varusa itilme için "adduktor momenti” kavramı kullanılmaktadır. Yüksek adduktor momenti olan hastalarda düşük adduktor momenti olan hastalara göre daha az başarılı sonuç alınmaktadır. Bu hasta grubunda valgus osteotomisinden sonra düzeltme derecelerinde kayıp ve sonuçta deformitenin tekrarı (nüksü) oluşabilir. Bu hastalarda önceden planlama ile deformitenin fazla düzeltilmesi fayda sağlayabilir. ${ }^{[13]}$

Patellofemoral eklemin hafif derecedeki dejeneratif değişiklikleri, özellikle retrotüberkül osteotomisi için kontrendikasyon oluşturmaz. MAKO uygulamalarından sonra, düzeltilen deformite derecesinin yarısı kadar tibial tüberkül aşağıya doğru iner. ${ }^{[13]}$ Patella infera (baja) durumunda tek planda (monoplanar) yapılan oblik osteotomiler için kontrendikasyon söz konusudur. ${ }^{[3,13]}$ Ancak tibial tüberkülün ve buna yapışan patellar tendonun proksimal fragmanda bırakıldığı iki planlı (biplanar) retrotüberkül osteotomi tekniği ile bu sorunun üstesinden gelindiği bildirilmiştir. ${ }^{[2]}$ Ameliyat öncesi patella infera saptanan hastalar ile ameliyat sonrası patella infera oluşumuna ve ileride gerekebilecek total diz protezi uygulamalarında patellanın eversiyon (dışa döndürme) problemlerine mani olabilmek için tibial tüberkülün proksimal fragmanda bırakıldığı osteotomi teknikleri tanımlanmıştır. ${ }^{[2-12]}$ Hernigou ve ark., tek planlı osteotomi uygulamalarında tibial eğim (slope) artmasına ve bunun sonucunda oluşabilecek patellar tendon boyunda nispi kısalığa mani olabilmek için osteotomi boşluğunun en arkasına kama yüksekliği en fazla, ortaya bunun $2 \mathrm{~mm}$ kısası, en öne de ortadakinden $2 \mathrm{~mm}$ daha kısa greft uygulamayı önermektedirler. ${ }^{[19]}$ Bölümün yazarları; farklı kama yüksekliğine sahip iki plak uygulamalarında, arkaya kama yüksekliği daha fazla olan plağı, öne ise kama yüksekliği daha düşük olanın kullanılmasını önermektedirler. ${ }^{[4-6]}$

\section{CERRAHI TEKNIK}

Spinal veya genel anestezi sonrası aynı veya karşı taraf kristasından greft alınacak şekilde ve ameliyat edilecek tarafa yüksek uyluk turnike sarılarak (ancak şişirilmeden) düz masada hasta hazırlanır. Planlandığı şekilde boyama ve örtme işlemleri yapılır.

Ameliyat; sırasıyla artroskopi, greft alımı ve tibial osteotomiden oluşur. Bazı uygulamalar, tek planlı (monoplanar) MAKO'da uygulandığı gibidir.

Artroskopi: Artroskopi öncesi turnike şişirilir. Eklem içini değerlendirmek için, yazarların da önerdiği gibi, artroskopik girişim ile başlanır. ${ }^{4-6,8,12,13,16-18,21]}$ Bölümün yazarları, düz masada bacağı sarkıtarak artroskopi uygulamaktadırlar. Gereken olgularda karşı portalden (giriş deliğinden) girilerek dejenere menisküs, düzensiz kıkırdak bölümleri ve osteofitler temizlenir. Varsa serbest cisimler çıkartılır. Subkondral kemiğin ortaya çıktığı olgularda kondroplasti (mikrokırık) uygulanır. Artroskopi esnasında, ameliyat öncesi yapılan radyolojik değerlendirmede saptanamayan, ancak artroskopik değerlendirmede saptanabilen ve karşı (lateral) kompartmanlarında subkondral kemiği açığa çıkartacak şekilde ileri evre kıkırdak lezyonu olan dizlerde osteotomi uygulamasından vazgeçilir. Artroskopi sonrası turnike açılır. Eklem yıkanır. Yazarlar artroskopi sonrası hemovak aspiratif dren uygulamaktadırlar. Mikrokırık uygulanan hastalarda, dren pasifte, sadece yerçekimi etkisinde kalacak şekilde uygulanır.

Greft alınması: Artroskopi sonrası, önceden planlanan distraksiyon miktarına göre ve boşluk bölgesini dolduracak miktarda, genellikle karşı taraf kristasından, tercihen tek korteks (monokortikal) veya iki korteks (bikortikal) greft alınır. Son uygulamalarda, greft alınma bölgesinde ameliyat sonrası ağrı oluşumunu azaltmak için, kristanın iç ve dış kemik yüzeyleri (tabulalar) sağlam bırakılarak, arasından spongioz yapıdaki greft alınması tercih edilmektedir. Greft alınma yüzeylerindeki kanamayı azaltmak için kemik mumu (bone-wax) uygulanabilir. Pasifte bir adet dren konarak katlar kapatılır.

Osteotomi: ${ }^{[4-6]}$ Skopinin kollarına, tercihen tek kullanımlık steril şeffaf kılıflar geçirilir ve hastanın ameliyat tarafının lateralinde (dış tarafında) ve ön-arka planda kontrol yapacak şekilde hazırlanır. Ameliyat bölgesi kurulanır, tekrardan boyanır ve drape ile örtülür. Artroskopi sonrası açılan turnike, steril esmark bandajıyla sarılarak ve bacaktaki kan boşaltılarak, osteotomi öncesi tekrardan şişirilir. Ekstansiyonda tutulan dizde orta hat üzerinden, eklem seviyesinin hemen altından başlayarak distale doğru uzunlamasına 7-8 cm'lik cilt kesisi uygulanır. Patellar tendonun yapıştığı tibial tüberkülü de içeren ve proksimal fragmanda bırakılan gaga şeklindeki çıkıntının lateraline ulaşabilmek için kesi orta hattan yapılmaktadır (Şekil 1). Aynı zamanda, ileride gerekebilecek total diz protezi uygulamalarında kesiye bağlı cilt problemi olmaması için de orta hattan düz kesi tercih edilmektedir.

Proksimal tibia medial bölümü üzerinde periost kısa parçası arkaya bakan ters "L" şeklinde kesilir. İç yan bağın yüzeyel lifleri bu kesi içinde kalır. Pes anserinusun yapışma yeri periost ile beraber tibiadan sıyrılır (Şekil 1). Böylece distraksiyon sonrası distal tibianın valgusa doğru yer değiştirmesi daha rahat olacaktır.

Retrotüberkül osteotomisi horizontal (yatay) ve vertikale yakın oblik yönlerde olmak üzere, iki planlı bir osteotomi yöntemidir. Yatay plandaki osteotomi hattı eklem çizgisinin 3,5-4 cm distalinden başlar ve başlangıcı sagittal planda ekleme (tibial eğime) paraleldir. 


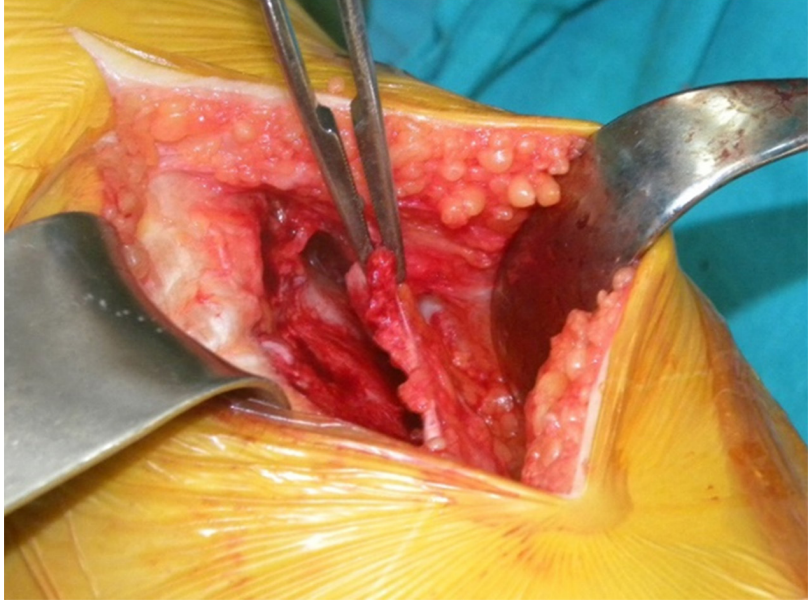

Şekil 1. Diz önünde orta hattan yapılan kesi ve pes anserinusun yapışma yerinin periost ile beraber ters "L" şeklinde tibiadan sıyrılarak uzaklaştırılması (pensetin ucunda).

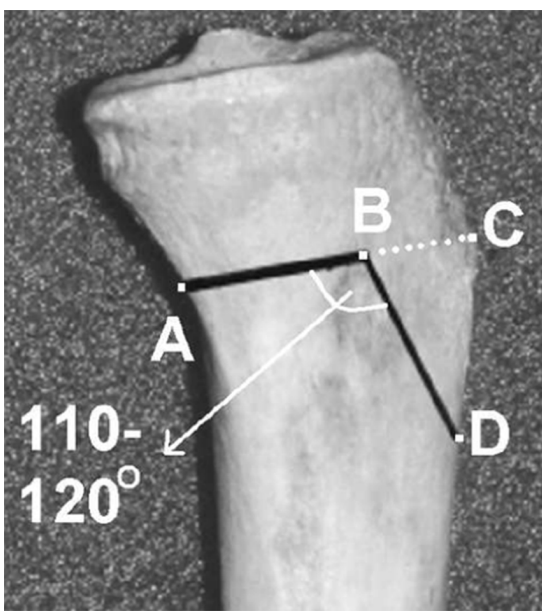

Şekil 2. Retrotüberkül osteotomisinin özellikleri. $\mathrm{Bu}$, iki planlı bir osteotomi olup yatay planda olanı [A-B] eklem aralığının 3,5-4 cm distalinden yapılır. Proksimal fragmanda bırakılan ve tibial tüberkülü de içeren gaganın uzunluğu [B-D] $\geq 2,5 \mathrm{~cm}$ ve gaganın kaidesi [B-C],

o bölümdeki tibia genişliğinin $[A-C] 1 / 3$ 'ü kadar olmalıdır. Yatay ve oblik osteotomi hatları arasındaki açı $(A B D)$ yaklaşık $110^{\circ}-120^{\circ}$ olmalıdır.
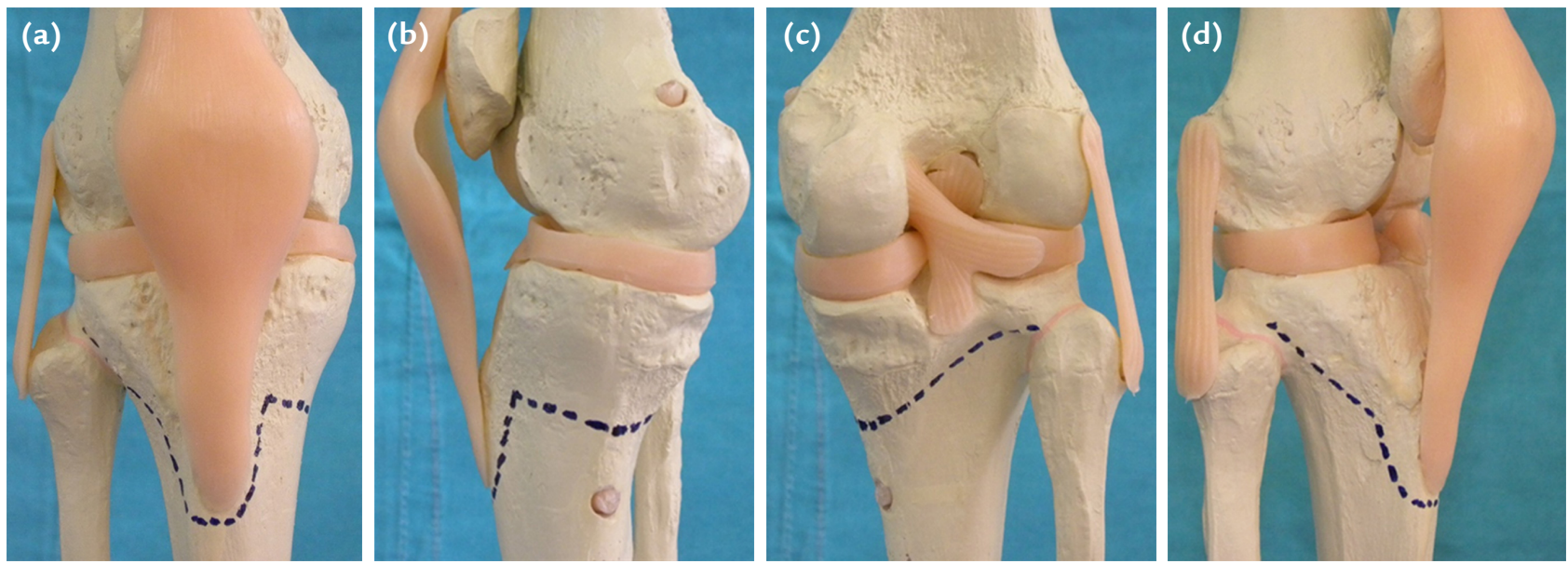

Şekil 3. a-d. Sağ diz maketinde retrotüberkül osteotomisinin çizimsel olarak gösterilişi: önden (a), iç taraftan (b), arkadan (c) ve dış/fibular taraftan (d) görünümler.

Medialden lateralde fibula başına doğru, direkt olarak veya kılavuz yardımıyla, oblik doğrultuda K-teli (Kirshner teli) gönderilir. Skopi kontrolünde seviye ve doğrultu kontrolü yapılır. Uygun ise, iki veya üç K-teli daha gönderilir. Skopi kontrolü ile, gönderilen kılavuz tellerinin yönü uygun bulunduğunda, bu tellerin altından uç kalınlığı ince olan kesici motorla (ısıya bağlı nekroz oluşmasın diye devamlı ıslatarak) medial korteks kesilir. Kesici uç kalınlığı ince olan bir osteotomla da aynı kesme işlemi yapılabilir. Medial korteksi keserken, anteriorda tibial tüberkülün kaidesinde yeterli kemik stoğu bırakacak şekilde, osteotomi tibia genişliğinin 2/3'lük mesafesinde sonlandırılmalıdır. Tibianın lateral korteksine veya lateral tibia platosuna uzanan kontrolsüz bir kırık oluşmaması için, kesme işlemi (osteotomi) eklem çizgisinin 1-1,5 cm distalinde ve lateral kortekse $1 \mathrm{~cm}$ mesafede sonlandırılmalıdır. Oblik planda tibial tüberkülün arkasından yapılan osteotomi ile tibial tüberkül ve buna yapışan patellar tendon proksimal fragmanda bırakılır. Bu planda yatay plandaki osteotomi hattı ile oblik osteotomi hattı arasındaki açı yaklaşık $110^{\circ}-120^{\circ}$ olmalıdır. Bu açı, tibial tüberkülü de içine alan gaganın kırılmaması için önemlidir. Oblik plandaki bu gaganın uzunluğu en az 2,5 cm olmalıdır (Şekil 2 ve Şekil 3). Bu mesafenin kısa olması burada kaynama sorunlarına neden olabilmektedir. Oblik plandaki kesi için, gaga bölümü koterle işaretlenerek mediolateral planda (iç taraftan dış tarafa doğru) önce K-telleri ile delinir. Sonra ince uçlu kesici motorla ya da osteotomla oblik plandaki kesi tamamlanır. Kalın uçlu kesici 

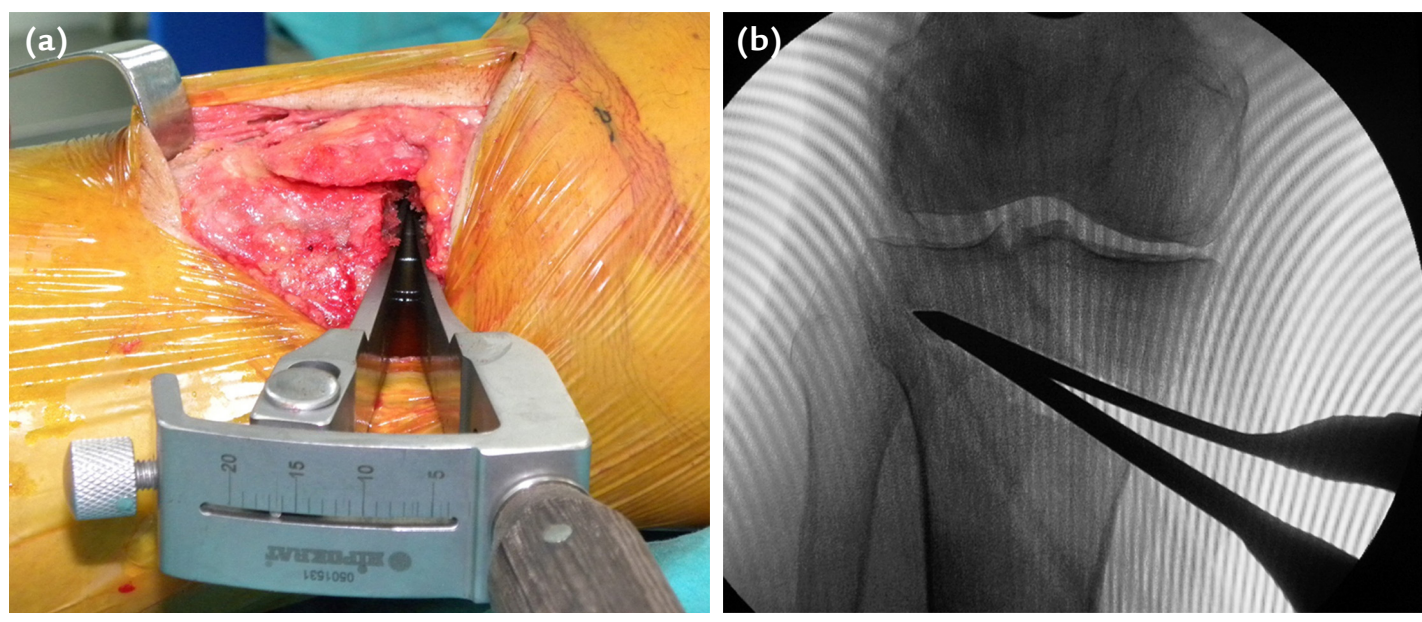

Şekil 4. a, b. Açı göstergeli distraktör (açıcı) kullanarak osteotomi yüzeylerinin birbirinden uzaklaştırılması: klinik görüntü (a) ve skopi görüntüsü (b).
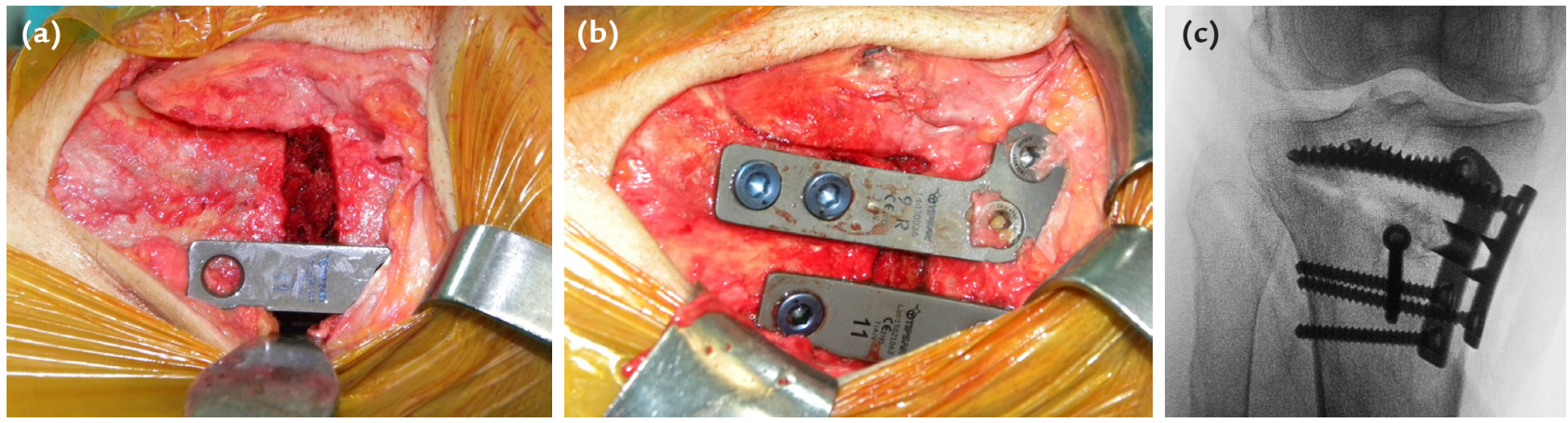

Şekil 5. a-c. Osteotomi boşluğuna (bu olgu için) önce arka bölüme iki delikli dikdörtgen plak (11 mm) yerleştirilmesi ve sonra boşluğun spongioz greftle doldurulması (a). Tibial eğim artışına engel olmak için ön tarafa kama yüksekliği daha az (9 mm) olan ters "L" kesitli dört delikli plağın uygulanması (b) (plak üzerlerindeki deliklerden, osteotomi hattının proksimalinde spongioz, distalinde kortikal vidalar uygulanmış; vida başları, kabarıklık yapmayacak şekilde, plak üzerindeki yuvalarına oturmuş; tibial tüberkül, ön-arka istikamette bir adet kortikal vida ile tespit edilmiş). Ameliyat esnasındaki skopi görüntüsü (c).

motor kullanılması kemikte kayba neden olacağı için düzeltme derecesini hesaplarken yanılmalara sebep olabilir. Son olarak, posteriordaki damar-sinir yapıları göz önünde bulundurularak (ekartörle korunarak) posterior korteks osteotomla kesilir. Damar-sinir yapılarını bölgeden uzaklaştırmak için, diz fleksiyonda iken de posterior korteks kesilebilir. Bu aşamalarda, ısıya bağlı nekroz ve sonuçta kaynama problemi oluşturmamak için tüm kesiler osteotomla da yapılabilir. Menteşe özelliğinden yararlanacak şekilde lateral korteksi sağlam bırakmak için azami özen gösterilir. Daha sonra kesilen kemik yüzeyleri birbirinden uzaklaştırılarak osteotomi boşluğu açılır. Osteotomi hattına skopi eşliğinde yönlendirilen iki osteotom arasına üçüncü ve gerekirse dördüncü osteotom yerleştirerek kontrollü distraksiyon uygulanabilir (oduncu kaması misali). Bir diğer yöntem olarak da, lateral tibia platosunda kırık oluşmasına mani olmak için, eklem yüzeyine paralel iki adet K-teli gönderildikten sonra distraksiyon (açma) uygulanabilir. ${ }^{[22]}$ Alternatif olarak, lateral tibia platosuna yakın plastik deformasyon alanından kontrollü distraksiyon yapabilmek ve lateral tibia platosu ile lateral korteks kırıklarına mani olabilmek için açılı distraktör kullanılabilir (Şekil 4). ${ }^{[23]}$

Ameliyat öncesi yapılan ölçümlere göre deformiteyi düzeltmek için uygulanacak plağın kama yüksekliğini hesaplarken, Hernigou'nun tanımladığı, osteotomi seviyesindeki tibianın genişliği ile arzu edilen düzeltme derecesi arasındaki bağlantıyı gösterir tablodan yararlanılabilir. ${ }^{[24]}$ Önceden hesaplanan oranda distraksiyon yapıldıktan sonra, açılı distraktör çıkartılarak oluşan boşluğa takoz vazifesini gören tekli kamalar yerleştirilir. Takozlar sırasıyla çıkartılarak aradaki alana uygun kama yüksekliğindeki kamalı plak/plaklar yerleştirilir. Plaklar sırasıyla yerleştirilirken distraksiyon bölgesi, önceden kristadan alınmış olan tercihen monokortikal veya bikortikal otogreft ile doldurulur (Şekil 5). Plaklar vidayla tespit edilmeden önce 

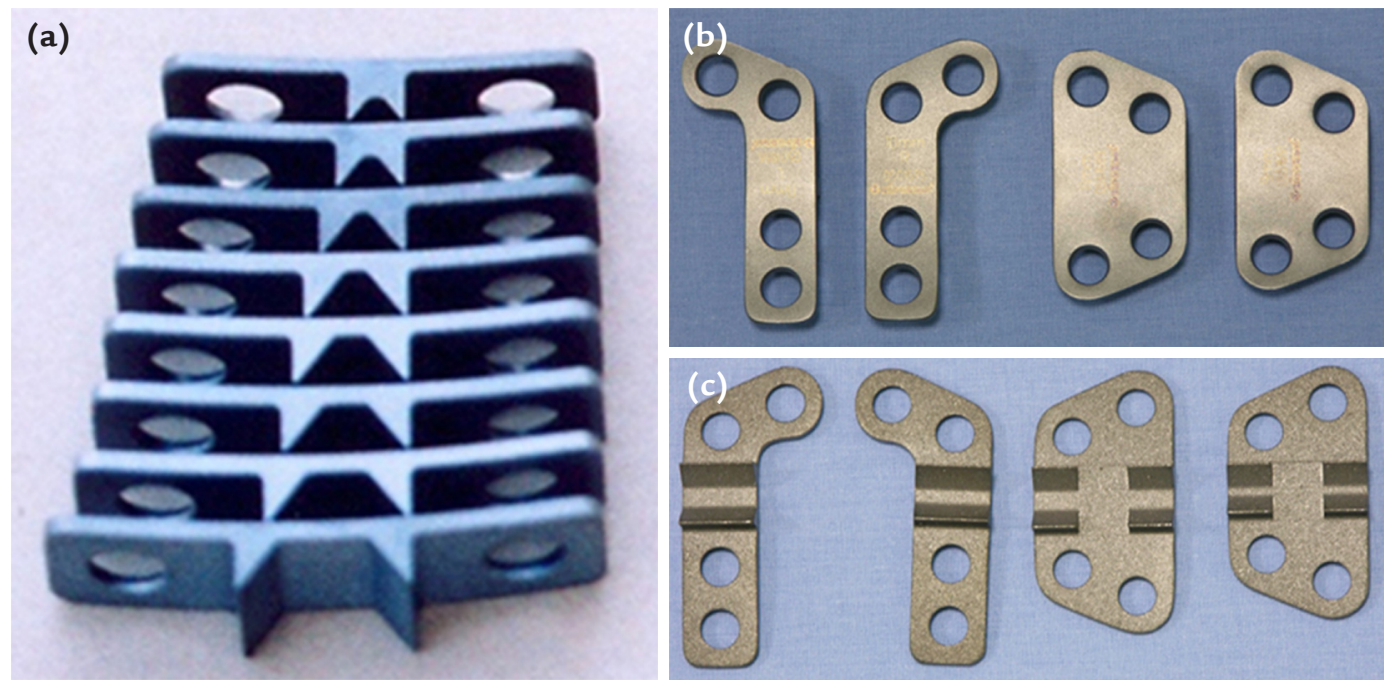

Şekil 6. a-c. Üretim aşamasında şekillendirilmiş farklı tasarımdaki kamalı plaklar. İki delikli plakların önden (a), "L" kesitli ve dört delikli plakların arkadan (b) ve önden (c) görünümleri.

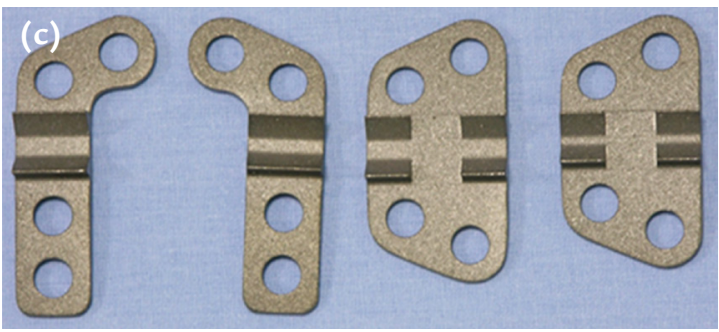

bu safhada düzeltme derecesini (mekanik ekseni taklit ederek) görmek için skopi kontrolünde femur başı ile ayak bileği orta noktalarını birleştiren kablo testi yapılabilir. Kablonun diz eklemi seviyesinde \%62,5 lateralden geçmesi arzu edilir. Ancak ameliyat öncesi ölçümler ayakta yapıldığından, ameliyat sırasında yatarak yapılan bu kablo testi yanılmalara sebep olabilir. Test yapılırken ayak tabanlarından yukarıya doğru itmek, yük vermeye benzer durum yaratabilir.

Kamalı plaklar farklı şekillerde tasarlanmıştı. ${ }^{[16-18]}$ Genellikle, tibial eğimde artma olmaması için arkaya kama yüksekliği daha fazla olan iki delikli dikdörtgen şeklindeki plak ve öne kama yüksekliği 1-2 mm daha az olan ters "L" şeklindeki dört delikli plak uygulanır. Vida deliklerinden proksimalde spongioz, distalde kortikal vidalar uygulanır. Tibial tüberkülün bulunduğu gaga şeklindeki çıkıntı ön-arka planda bir adet kortikal vida ile çift korteks tibiaya tespit edilebilir (Şekil 5b). Turnike açılarak kanama kontrolü yapılır. Kapatma işlemi esnasında, ameliyatın ilgili bölümünde proksimal tibianın medial bölümünü açığa çıkartmak için ters "L" şeklinde kesilerek sıyrılan periost, pes anserinusun yapışma yeri ile bağlantılı yumuşak dokunun sadece uzun bacağı dikilir. Kısa bacağı içerisinde iç yan bağın yüzeysel lifleri de olacağından ve dikilirse ekleme sıkıştırıcı etki yaratacağı için, sadece yaklaştıııcı dikişlerle tespit edilir.

\section{Plaklar [4-6,16-18]}

Tasarımları bir no.lu yazar (IE) tarafindan yapılan titanyum plaklar, osteotomi yüzeylerini içeriden üçgen şeklindeki ve $4 \mathrm{~mm}$ derinliğindeki kamalarla destekleyen bir yapıya sahip olup bu kamaların yükseklikleri 5 ,
$6,7,5,9,10,11,12,5$ ve $15 \mathrm{~mm}$ arasında değişmektedir. Plaklar iki delikli dikdörtgen, dört delikli dikdörtgen ve dört delikli ters " $\mathrm{L}$ " şeklinde tasarlanmış olup uygulama esnasında tibia üst ucunun medial tarafının anatomik eğimine uyum sağlayacak şekilde üretim aşamasında şekillendirilmiştir. Osteotominin proksimalinden spongioz, distalinden kortikal vida uygulayacak ve vida başları plak üzerinde kabarıklık yapmayacak şekilde vida yuvaları açılmıştır. Plak kalınlığı $2 \mathrm{~mm}$ olup dar olanlar $12,5 \mathrm{~mm}$ ve geniş olan $25 \mathrm{~mm}$ genişliğindedir. Vidalar, plak üzerindeki vida yuvasına oturduklarında plak yüzeyini aşmayacak şekilde (cilt altında kabarıklık yapmayacak şekilde), farklı boylarda kortikal ve spongioz özellikte üretilmiştir (Hipokrat/Türkiye, TR2002 02021Y) (TIPSAN/Türkiye) (Şekil 6). Genel olarak, eğim artmasına mâni olmak için osteotomi aralığının arka tarafına kama yüksekliği daha fazla olan iki delikli dikdörtgen plak ve ön tarafına da kama yüksekliği 1-2,5 mm daha az olana "L" kesitli dört delikli plak olmak üzere çift plak uygulanmaktadır. Eğim değişikliğinin yapılmayacağı durumlarda, dört delikli dikdörtgen tek plak da kullanılabilir (Şekil 5 ve 6).

\section{Kemik Grefti Uygulaması (Genel Bilgi)}

Hernigou ve ark. distraksiyon sonrası oluşan boşluğun iliak kristadan alınan kortikospongioz yapıdaki greft ile doldurulmasını önermiştir. ${ }^{[24]}$ Bazı yazarlar $7,5 \mathrm{~mm}$ ve altındaki distraksiyonlarda (açmalarda), Lobenhoffer ve ark. ise $15 \mathrm{~mm}$ kadar açtıkları osteotomilerde greft kullanmanın gerekli olmadığını bildirmişlerdir. ${ }^{[3,13,20]}$ Osteotomi aralığını 7,5-10 mm açmada tibiadan alınan lokal spongioz greft, $12,5 \mathrm{~mm}$ 
ve üzerindeki açmalarda spongioz kemikle güçlendirilmiş hidroksiapatit/trikalsiyumfosfat karışımını kullanan yazarlar vardır. ${ }^{[3,20]}$ Otogreft kullanılması, alındığı bölgede ameliyat sonrası ağrıya, hematom oluşumuna, sepsise ve kıyafet giyerken rahatsızığa neden olabilir. ${ }^{[24]}$ Hernigou ve Ma bu komplikasyonları önlemek için akrilik kemik çimentosu, Koshino ve ark. ise hidroksiapatit dolgu maddesi ve fibuladan rezeke edilen kortikal kemiğin kullanımı ile iyi sonuçlar bildirmişlerdir. ${ }^{[15,24]}$ Bölümün yazarları tüm olgularında aynı veya karşı taraf kristasından elde edilen, tercihan monokortikal veya bikortikal otogreft kullanmaktadırlar (Şekil 5a). Greft alınma (donör) bölgesinde ileride ağrı ve diğer problemlere neden olmamak için trikortikal greft almamalıdır. Greftler distraksiyon alanına yerleştirildikten sonra büyüme faktörleri içeren kan pıhtılarını ortamdan uzaklaştırmamak için bölge yıkanmaz ve hemovak aspiratif dren pasif olarak uygulanır. ${ }^{[4-6,16-18]}$

\section{Tibial eğimin ayarlanması}

Ameliyat öncesi; ekstansiyon tam ise tibial eğim değiştirilmez. Ekstansiyon kısıtlıysa veya anterior instabilite varsa tibial eğim azaltılır. Posterior instabilite veya hiperekstansiyon varsa tibial eğim artırılır. ${ }^{[3,21]}$

\section{Ameliyat Sonrası Takip}

Ameliyat sonrası basınçlı Jones bandajı (sargısı) uygulanır. Ameliyat öncesi başlanan 1. kuşak sefalosporin uygulamasına iki gün devam edilir.

Düşük molekül ağırlıklı heparin uygulamasına hastanede yattığı süre içinde devam edilip taburcu edildikten sonra 81 veya $100 \mathrm{mg}$ asetil salisilik asit (Aspirin) uygulanmaya başlanır.

Drenlerden gelen miktara göre değişmek üzere, 24-48 saat içerisinde drenler alınır. Drenler alındıktan sonra dizden menteşeli breys uygulanır. Bir çift koltuk değneği ya da yürüteç ile yük vermemek kaydıyla ayağa kaldırılır.

Drenler alındıktan sonra devamlı pasif hareket (CPM) sağlayıcı cihaz ile ve ilave olarak yatak kenarın$\mathrm{da}$ (breyssiz) diz hareketlerine başlanır. illk haftada $90^{\circ}$ diz hareketine ulaşmak hedeflenir. İlerleyen günlerde diz ekleminde tam ekstansiyon ve yapabildiği kadar fleksiyon hareketi hedeflenir.

Röntgen kontrolüyle, bir ay dolunca kısmi ve ikinci ay bitiminde koltuk değnekleriyle tam yük verdirilir. Koltuk değnekleri teker teker bıraktırılır.

\section{KOMPLIKASYONLAR}

Tek planlı açık kama osteotomisinde görülebilen genel komplikasyonlar iki planlı retrotüberkül osteotomisinde de görülebilir. Lateral kortekste kırık, lateral tibia platosuna uzanan eklem içi kırık, kaynama gecikmesi ya da kaynamama, plak-vida yetmezliği, erken-geç enfeksiyon, derin ven trombüsü, pulmoner emboli gelişebilir. Ameliyat sonrası elde edilen düzeltme derecelerinde kayıp oluşabilir. ${ }^{[3-6,13,15,16-18,25,26]}$

Retrotüberkül osteotomisininde tibial tüberkülün (TT) de içinde bulunduğu gaga bölgesinde kırık oluşabilir. Tibia proksimali düz olmayıp sagittal plandaki metafizer eğim açısı akılda tutulmalıdır. Bu bölge patellar tendonun yapışma yerinin proksimalinde kaldığı için, yatay ve dik/oblik osteotomi hatları birleştirilirken, yatay osteotomi genişliğinin tibia genişliğinin 2/3'ünü geçmeyecek şekilde plan yapılmalıdır (Şekil 2).

\section{Yazarların komplikasyon deneyimleri}

Olgularımızdan hiçbirinde TT'yi de içeren gagada kırık oluşmadı. Ancak konuyla ilgili yaptığımız kadavra çalışmasında, proksimal tibia metafizer bölgedeki sagittal plandaki eğim göz önüne alınmadığında ya da iki planlı osteotominin kolları arasındaki açı $90^{\circ}$ ve altına indiğinde TT-gaganın kırıldığını saptadık. ${ }^{[27]}$ Başlangıçta orijinal teknikten farklı olarak TT-gagayı tespit vidası uygulamaz iken, takip grafilerinde bu bölümde kaynama gecikmesi saptadığımız bazı olgularımızdan sonra, biz de orijinal yöntemde olduğu gibi gagayı ön-arka planda tespit eden kortikal vida uygulamaya başladık.

Serimizdeki olgulardan günde üç paket sigara içen bir hastamızda osteotomi hattının kaynamadığı saptandı. Revizyon ameliyatı gerekti. Sigara içen hastaların sigarayı bıraktıktan 3-4 ay sonra ameliyat edilmelerinin uygun olduğunu düşünmekteyiz.

Kullanılan plak-vida tespit sistemiyle ilgili yetmezlik oluşabilir. Bizim olgularımızın hiçbirinde plak ve vidalarda kııılma saptanmadı. Yaptığımız biyomekanik çalışmada kamalı plakların uygulanan maksimum yüklenme kuvvetlerine karşı yeterli güçte oldukları gösterilmiştir. ${ }^{[28]}$

Bir olgumuzda turnike kullanımı sonrası rabdomiyoliz gelişti. Yoğun bakım ve nefroloji desteği ile erken müdahale sonrası hasta sorunsuz iyileşti. ${ }^{[29]}$

\section{RETROTÜBERKÜL PTO UYGULAMASININ KLINIK SONUÇLARI}

Tibial tüberkülün distal fragmanda bırakıldığı iki planlı osteotomi uygulayan Lobenhoffer ve ark. ${ }^{[3]}$ ile Brinkman ve ark. ${ }^{[30]}$ gibi bazı yazarlar, düzeltmenin fazla yapılması gereken durumlarda veya patellofemoral problemi olan hastalarda, rutin olarak uyguladıkları ve tibial tüberkülün distal fragmanda bırakıldığı iki planlı osteotomi uygulamaları dışına 
çıkarak, tibial tüberkülün proksimal fragmanda bırakıldığı modifiye tekniği uyguladıklarını bildirdiler. ${ }^{[3,30]}$ Gaasbeek ve ark., ortalama yaşları 48 (27-64) olan ve 17 olgudan oluşan serilerinde, tibial tüberkülün proksimal fragmanda bırakıldığı iki planlı osteotomiyle başarılı sonuçlar aldıklarını, özellikle de medial açık kama osteotomi uygulamalarından sonra gelişebilecek patellanın aşağıya yer değiştirmesinin (patella infera) bu uygulama ile önüne geçildiğini ve daha fazla düzeltme gereken olgularda bu yöntemin daha rahat uygulanır olduğunu bildirdiler. Tespiti Tomofix plağı ile yaptıklarını ve distrakte alanı tri-kalsiyum fosfat yapısındaki sentetik greft ile doldurduklarını belirten yazarlar ameliyat sonrası hemen diz hareketlerine başladıklarını, ilk altı hafta çift koltuk değneği ile $10 \mathrm{~kg}$ yük vermeye ve altı hafta dolunca tam yüklenmeye izin verdiklerini tanımladılar. Tibial tüberkülü ön-arka planda bir adet vidayla tespit ettiklerini belirten yazarlar bir olguda tibial tüberkülün kırıldığını bildirdiler. ${ }^{[2]}$

Hopwood ve ark., ${ }^{[7]}$ ortalama yaşları 39,6 olan ve 12 hastadan oluşan çalışmalarında tespiti medialden Tomofix plakla yaptıklarını bildirdiler. Ameliyat sonrası hemen diz hareketlerine başladıklarını, breys kullanmadıklarını belirten yazarlar altı haftaya kadar sadece yere temasa müsaade ettiklerini, yük verdirmediklerini ve bir yıllık takip süresi sonunda patella yüksekliğinde istatistiksel olarak anlamlı bir değişiklik olmadığını belirttiler. Yazarlar sonuç olarak, sadece ameliyat öncesi patella bajası olan hastalarda değil, PTO uygulanması planlanan tüm hastalarda, tibial tüberkülün proksimal fragmanda bırakılması ile başarılı sonuçlar alınabileceğini bildirdiler. ${ }^{[7]}$

Longino ve ark.[11], tibial tüberkülün proksimal fragmanda bırakıldığı ve tek planlı klasik osteotominin uygulandığı, 29'ar vakadan oluşan, ortalama yaşları sırasıyla 46 ve 49 olan iki seriyle ilgili kıyaslamalı çalışmanın sonuçlarını bildirdiler. Alışılmış klasik medial açık kama osteotomi uygulamalarının, patellaya oranla eklem hattını yükselterek, tibial tüberkül ile tibiofemoral eklem hattı arasındaki mesafeyi artırdığını belirtmişlerdir. Tibial tüberkülün proksimal fragmanda bırakıldığı seride, patella/patellar tendon oranlarındaki değişiklik oranlarının minimalize edildiği ve ameliyat öncesi koronal plan deformitesi daha fazla olan olgularda düzeltmenin elde edilebildiğini bildirdiler. ${ }^{[11]}$

\section{YAZARLARIN TECRÜBELERI}

Yazarların konuyla ilgili klinik deneyim ve tecrübeleri önceki çalışmalarında aktarılmıştır. ${ }^{[4-6,25,26]}$

2005-2008 arası ilk deneyimlerin değerlendirildi-

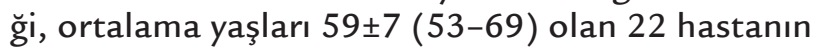

23 dizi ile ilgili ve ortalama $37 \pm 11$ ay (19-58 ay) takibi yapılan seride femorotibial anatomik eksen ameliyat öncesi $185,35 \pm 2,48$ iken ameliyat sonrası $174,57 \pm 1,86$ olarak değerlendirilmiştir (Yazarlar o dönem ortorontgenografi yerine uzun kasete çekilen grafiler üzerinden değerlendirme yaptıklarından, ölçümler anatomik eksene göre yapılmıştır). Patellar tendon/patella uzunluğu oranları InsallSalvati, Blackburn-Peel ve Caton indeksi yöntemlerine göre ameliyat öncesi ve sonrası değerlendirilmiş, sırasıyla $1,14 \pm 0,16,0,78 \pm 0,28,0,85 \pm 0,12$ ve $1,14 \pm 0,16,0,73 \pm 0,13,0,84 \pm 0,13$; tibial slope ameliyat öncesi $12,74^{\circ} \pm 2,53^{\circ}$ iken ameliyat sonrası $13,78^{\circ} \pm 2,73^{\circ}$; Hospital for Special Surgery (HSS) skoru ameliyat öncesi $59 \pm 5$ iken ameliyat sonrası $88 \pm 7$ olarak değerlendirilmiştir. Anatomik eksende ortalama $11^{\circ}$ düzeltme ve hastanın HSS skorlamasında ortalama 29 puan düzelme elde edilmiş, patellar tendon/patella boyu oranlarında önemli bir değişiklik oluşmamıştır. ${ }^{[4]}$

Yazarların tek planlı (ortalama yaşları $55 \pm 9$, ortalama $40,6 \pm 7$ ay takipli 50 hastanın 56 dizi) ve iki planlı retrotüberkül (ortalama yaşları $57 \pm 7$, ortalama $38 \pm 5$ ay takipli 28 hastanın 32 dizi) medial açık kama osteotomisini kıyasladıkları bir başka çalışmada; her iki yöntemin de varus gonartrozunun tedavisinde etkili birer yöntem olduğunu, ancak iki planlı retrotüberkül osteotomisinin radyolojik olarak patella infera oluşumunu ve tibial slope değişikliklerini önlediğini belirtmişlerdir. ${ }^{[5]}$

Yukarıda, cerrahi bölüm tanımlanırken ameliyat esnasındaki görüntüleri verilen 74 yaşındaki erkek hastamızın ameliyat öncesi ve sonrası görüntüleri. Hastanın diğer (sol) tarafına da üç yıl öncesi retrotüberkül proksimal tibia MAKO uygulanmıştır. Elde edilen memnuniyet ve başarı nedeniyle, aktif olan hastamızın diğer (sağ) tarafına da retrotüberkül proksimal tibia MAKO uygulandı (Şekil 7).

\section{SONUÇ}

Ameliyat öncesi yapılan değerlendirmelerde patella infera saptanmayan olgularda, tibial tüberkülün proksimal fragmanda bırakıldığı proksimal tibia medial açık kama iki planlı retrotüberkül osteotomi uygulaması patellar tendon boyunda değişiklik yapmaz. Patellar tendon boyunda değişiklik oluşmadığı için, tekniğe bağlı olarak PF eklem basıncında artma beklenmez. Bu nedenlerle, medial kompartman osteotartritine ilave olarak PF problemi olan olgularda proksimal tibia medial açık kama iki planlı retrotüberkül osteotomi uygulaması ile başarılı sonuçlar alınır. 

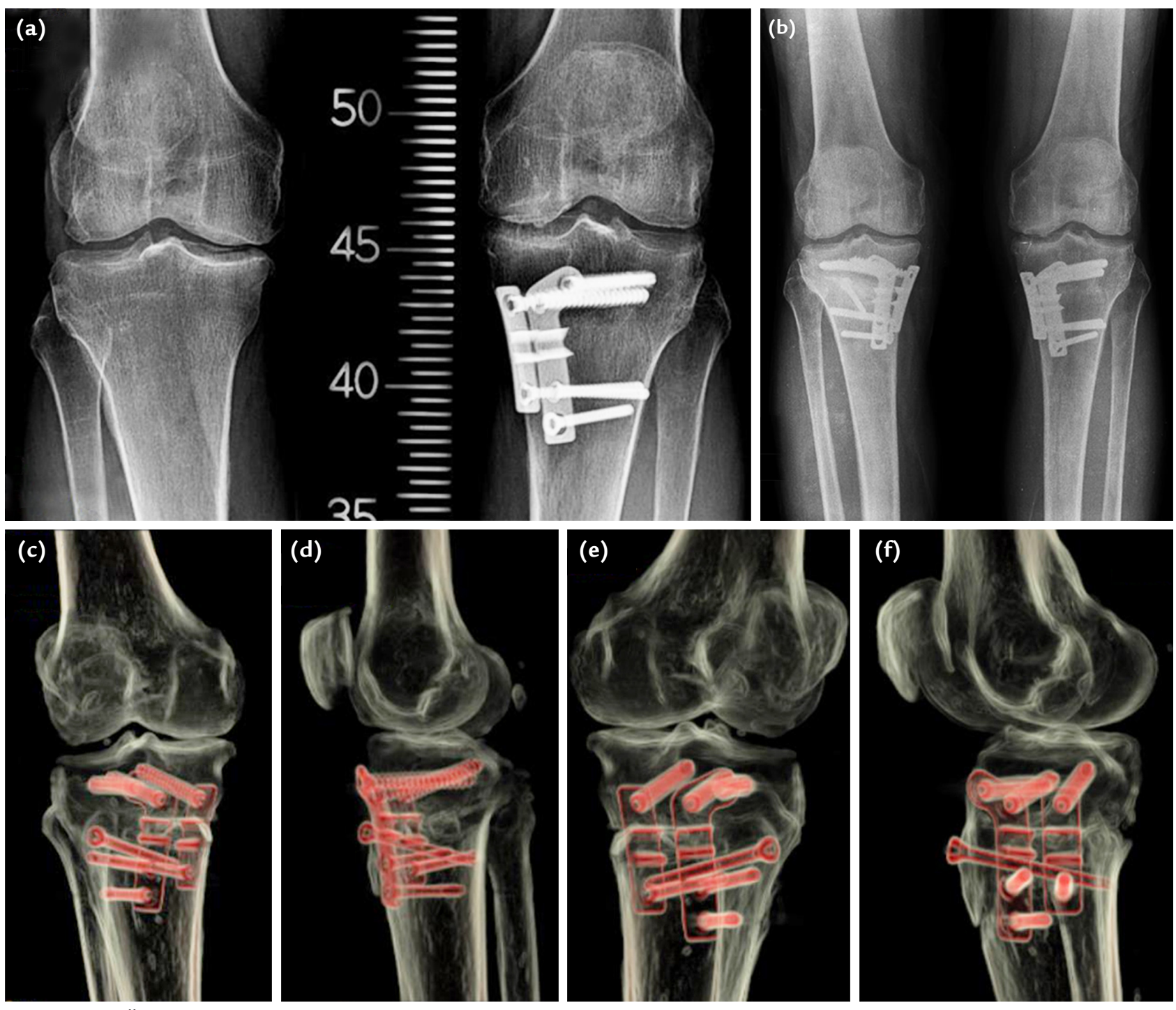

Şekil 7. a-f. Üç yıl öncesi sol tarafına da PTMAKO uygulanan 74 yaşında, erkek hasta: Sağ tarafın, ameliyat öncesi (a) ve ameliyat sonrası (b) düz grafileri. Ameliyat sonrası üç boyutlu (volume rendering) grafileri (c-f).

\section{KAYNAKLAR}

1. Murphy SB. Tibial osteotomy for genu varum: Indications, preoperative planning, and technique. Orthop Clin North Am 1994;25(3):477-82.

2. Gaasbeek RD, Sonneveld $H$, van Heerwaarden RJ, Jacobs WC, Wymenga AB. Distal tuberosity osteotomy in open wedge high tibial osteotomy can prevent patella infera: a new technique. Knee 2004;11(6):457-61. Crossref

3. Lobenhoffer P, De Simoni C, Staubli AE. Open-wedge high tibial osteotomy with rigid plate fixation. Tech Knee Surg 2002;1(2):93-105. Crossref

4. Esenkaya I, Unay K. Proximal medial tibial biplanar retrotubercle open wedge osteotomy in medial knee arthrosis. Knee 2012;19(4):416-21. Crossref
5. Elmalı N, Esenkaya I, Can M, Karakaplan M. Monoplanar versus biplanar medial open-wedge proximal tibial osteotomy for varus gonarthrosis: a comparison of clinical and radiological outcomes. Knee Surg Sports Traumatol Arthrose 2013;21(12):2689-95. Crossref

6. Turkmen I, Esenkaya I. A patellar tendon length conservation method: Biplanar retrotubercle open-wedge proximal tibial osteotomy. North Clin Istanb 2018;5(3):246-53. Crossref

7. Hopwood S, Khan W, Agarwal S. The biplanar open wedge high tibial osteotomy preserving the tibial tubercle. J Orthop Sci 2016;21(6):786-90. Crossref

8. Horikawa T, Kubota K, Hara S, Akasaki Y. Distal tuberosity osteotomy in open-wedge high tibial osteotomy does not exacerbate patellofemoral osteoarthritis on arthroscopic evaluation. Knee Surg Sports Traumatol Arthrosc 2019. Crossref 
9. Kloos F, Becher C, Fleischer B, Feucht MJ, Hohloch L, Südkamp N, Niemeyer P, Bode G. High tibial osteotomy increases patellofemoral pressure if adverted proximal, while open-wedge HTO with distal biplanar osteotomy discharges the patellofemoral joint: different open-wedge high tibial osteotomies compared to an extra-articular unloading device. Knee Surg Sports Traumatol Arthrosc 2019;27(7):2334-44. Crossref

10. Krause M, Drenck TC, Korthaus A, Preiss A, Frosch KH, Akoto R. Patella height is not altered by descending medial open-wedge high tibial osteotomy (HTO) compared to ascending HTO. Knee Surg Sports Traumatol Arthrosc 2018;26(6):1859-66. Crossref

11. Longino PD, Birmingham TB, Schultz WJ, Moyer RF, Giffin JR. Combined tibial tubercle osteotomy with medial opening wedge high tibial osteotomy minimizes changes in patellar height: a prospective cohort study with historical controls. Am J Sports Med 2013;41(12):2849-57. Crossref

12. Ogawa $\mathrm{H}$, Matsumoto $\mathrm{K}$, Yoshioka $\mathrm{H}$, Sengoku $\mathrm{M}$, Akiyama $\mathrm{H}$. Distal tibial tubercle osteotomy is superior to the proximal one for progression of patellofemoral osteoarthritis in medial opening wedge high tibial osteotomy. Knee Surg Sports Traumatol Arthrosc 2019. Crossref

13. Franco V, Cerullo G, Cipolla M, Gianni E, Puddu G. Open wedge high tibial osteotomy. Tech Knee Surg 2002;1(1):4353. Crossref

14. Lobenhoffer P, Agneskirchner JD. Improvements in surgical technique of valgus high tibial osteotomy. Knee Surg Sports Traumatol Arthrosc 2003;11(3):132-8. Crossref

15. Koshino T, Murase T, Saito T. Medial opening-wedge high tibial osteotomy with use of porous hydroxyapatite to treat medial compartment osteoarthritis of the knee. J Bone Joint Surg Am 2003;85(1):78-85. Crossref

16. Esenkaya I. Fixation of proximal tibia medial opening wedge osteotomy using plates with wedge [Proksimal tibia medial açık kama osteotomisinde kamalı plak uygulaması]. Acta Orthop Traumatol Turc 2005;39(3):211-23. http://www. aott.org.tr/en/fixation-of-proximal-tibia-medial-openingwedge-osteotomy-using-plates-with-wedges-164753

17. Esenkaya I. Opening wedge proximal tibial osteotomy using the plate with wedge. Tech Knee Surg 2006;5(4):261-73. Crossref

18. Esenkaya I, Elmali N. Proximal tibia medial open-wedge osteotomy using plates with wedges: early results in 58 cases. Knee Surg Sports Traumatol Arthrosc 2006;14(10):955-61. Crossref

19. Hernigou Ph, Medevielle D, Debeyre J, Goutallier D. Proximal tibial osteotomy for osteoarthritis with varus deformity: A ten to thirteen-year follow-up study. J Bone Joint Surg Am 1987;69(3):332-54. Crossref
20. Fowler PJ, Tan JL, Brown GA. Medial opening wedge high tibial osteotomy: How I do it? Op Tech Sports Med 2000;8(1):328. Crossref

21. Staubli AE, De Simoni C, Babst R, Lobenhoffer P. TomoFix: a new LCP-concept for open wedge osteotomy of the medial proximal tibia - early results in 92 cases. Injury 2003;34(Suppl 2):B55-62. Crossref

22. Esenkaya İ, Elmalı N, Mısırlıoğlu M, Ertem K. Proksimal tibia medial açık kama osteotomisinde lateral plato kırı̆̆ı oluşumunu önlemek için alternatif uygulama. Dana tibialarında deneysel çalışma. İnönü Üniversitesi Tıp Fakültesi Derg 2005;12(2):715. https://arastirmax.com/en/system/files/dergiler/5674/ makaleler/12/2/arastirmax-proksimal-tibia-medial-ac-ik-kamaosteotomisinde-lateral-plato-kirigi-olusumunu-onlemek-icinalternatif-uygulama-dana-tibialarinda-deneysel-calisma.pdf

23. Esenkaya I. A new distractor with angle-scale for proximal tibia medial opening wedge osteotomy. Knee Surg Sports Traumatol Arthrosc 2006;14(5):443-6. Crossref

24. Hernigou P, Ma W. Open wedge tibial osteotomy with acrylic bone cement as bone substitute. Knee 2001;8(2):103-10. Crossref

25. Esenkaya I, Poyanlı O, Gökçen HB. İki planlı "Retrotüberkül” Medial Açık Kama Valgus Osteotomisi ve Kamalı Plak Uygulaması. İçinde: Esenkaya I, Özenci M, Kocabey $\mathrm{Y}$, Bombacı H, Köse Ö. Diz Çevresi Osteotomileri, Bölüm 14. İstanbul: İstanbul Tıp Kitabevi; 2018. ss.115-25.

26. Esenkaya I, Unay K, Türkmen i. Medial Gonartrozda Retrotüberkül Açık Kama Ostetomisi. Turkiye Klinikleri J Orthop \& Traumatol-Special Topics 2013;6(4):79-85.

27. Esenkaya I, Elmalı N, Mısırlıoğlu M, Ertem K, Atasever A. Tibial tüberkülün proksimal fragmandabırakıldığıproksimaltibiamedial açık kama osteotomisi: anatomik çalışma. Inönü Üniversitesi Tıp Fakültesi Derg 2005;12(3):153-7. http://openaccess.inonu.edu. tr:8080/xmlui/bitstream/handle/11616/1479/2005_12_3_2. pdf? sequence $=1$ \&isAllowed $=y$

28. Esenkaya I, Misirlioglu M, Kelestemur MH, Elmali $\mathrm{N}$, Fadillioglu E. Biomechanical evaluation of different fixation plates in medial opening upper tibial osteotomy. Knee 2007;14(1):46-50. Crossref

29. Türkmen I, Esenkaya I, Unay K, Akçal MA. Rhabdomyolysis after tourniquet use in proximal tibial osteotomy: a case report and review of the literature. Acta Orthop Traumatol Turc 2015;49(3):338-41. Crossref

30. Brinkman JM, Lobenhoffer P, Agneskirchner JD, Staubli AE, Wymenga $A B$, van Heerwaarden RJ. Osteotomies around the knee: patient selection, stability of fixation and bone healing in high tibial osteotomies. J Bone Joint Surg Br 2008;90B(12):1548-57. Crossref 